Journal of Agricultural Sciences
(Tarim Bilimleri Dergisi)

\title{
The performance of Trichogramma (Hymenoptera: Trichogrammatidae) Parasitoids Feeding on Honey Sources
}

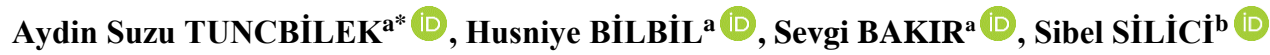 \\ ${ }^{a}$ Department of Biology, Faculty of Sciences, Erciyes University, 38039 Kayseri, TURKEY \\ ${ }^{b}$ Department of Animal Biotechnology, Seyrani Faculty of Agriculture, Erciyes University, 38039 Kayseri, TURKEY \\ ARTICLE INFO \\ Research Article \\ Corresponding Author: Aydin Suzu TUNCBILEK, E-mail: tunca@erciyes.edu.tr \\ Received: 12 March 2020 / Revised: 18 May 2020 / Accepted: 04 June 2020 / Online: 04 December 2021
}

\section{ABSTRACT}

The effectiveness of parasitoids as organism for biological control is at times limited by food sources. Most of parasitoids rely on carbohydrate foods to enhance their longevity and reproductive capacity. Honey is the miraculous product of honey bees and is naturally delicious. A preliminary study was conducted on the use of different kinds of honey as food sources for the Trichogramma species. The value of honey as a food source for Trichogramma was evaluated by testing the influence of several honey diets on parasitism and longevity in the laboratory. The most commonly available honey is made from a variety of flowers, pine, citrus, chestnut, sunflower, and cotton. Trichogramma females fed on

Keywords: Fecundity, Honey, Longevity, Parasitization, Trichogramma chestnut and sunflower honey parasitized relatively more than when fed on citrus honey. Trichogramma females fed on flower, sunflower, and citrus honey survived drastically longer than females fed on chestnut and pine honey. These results showed that supplying sugar, sunflower, and flower honey to Trichogramma resulted in greater longevity and total fecundity. Overall, feeding Trichogramma females on different kinds of honey had a negligible effect on parasitization but did certainly affect longevity. Of the Trichogramma species evaluated, T. brassicae appears to be the most suitable parasitoids regarding high parasitization and longer life span.

(C) Ankara University, Faculty of Agriculture

\section{Introduction}

There are many beneficial insect species that can be used in biological control. Among these beneficial insects, parasitoids are a very important group. The Trichogramma species in this group is of great importance in biological control. As a favorable method for reducing egg hatching and consequent harm caused by larvae, the augmentative release of lab-reared trichogrammatid egg parasitoids has been used (Smith 1996). The production of the Trichogramma species in the laboratory is cheap and easy. In many countries, these parasitoids are produced in bulk and are used against various pests, especially Lepidoptera (Hassan 1993; van Lenteren 2012).

The efficiency of parasitoids as organism for biological control is sometimes limited by food sources, and the availability of food plays a major role in determining the effectiveness of parasitoids as control agents. The Trichogramma species is fed with nectar and pollen in nature (Wellinga \& Wysoki 1989), and these foods are known to be effective on the longevity of parasitoids (Hohmann et al. 1989; Shearer \& Atanassov 2004), parasitism (Somchoudhury \& Dutt 1988; Shearer \& Atanassov 2004) and adult sex ratio. These natural food sources are replaced by honey and sucrose in the laboratory. Many studies have reported that feeding Trichogramma adults significantly increases fecundity and longevity in the laboratory (Ashley \& Gonzales 1974; Bourarach \& Hawlitzky 1989).

Honey contains many substances and consists of sugar, proteins, vitamins, and minerals (Alavarez-Suarez et al. 2009). It also covers antimicrobials and antioxidants (Echingo \& Takenaka 1974; Martos et al. 2000; Gheldof et al. 2002). The use of extra food sources to improve biological control services for parasitoids and predators has been extensively discussed (Heimpel $\&$ Jervis 2005). It was indicated that the providing of food in the field can help parasitoids maintain their sugar resources and increase fecundity and parasitism (Tena et al. 2015).

Despite the significance and valuable information that laboratory work provides in selecting potential candidates for biological control, the real value of these studies is still being discussed (Waage 1990; Jervis \& Kidd 1992). These studies show the potential value of adult foods, particularly when compared to the Trichogramma spp. In this study, we compared the suitability of the various types of honey as food sources consumed by Trichogramma spp. The goal of this research was to find 
out if different food obtainability would likely be a significant point in the field's success by evaluating the response to a honey diet under laboratory conditions.

\section{Material and Methods}

\subsection{E. kuehniella Rearing Procedure}

Mediterranean flour moths (MFM), Ephestia kuehniella Zeller 1879 (Lepidoptera: Pyralidae) has been reared in our laboratory since 2015. The MFM were reared on a mixture of wheat flour, wheat germ and yeast (Marec et al. 1999). While rearing, the moth cultures were kept in a rearing room maintained at $27 \pm 1{ }^{\circ} \mathrm{C}$ and $70 \pm 5 \% \mathrm{RH}$ under $16 \mathrm{~h}$ light followed by $8 \mathrm{~h}$ darkness $(16$ L: 8 D). For obtaining host eggs, new emerged adults of MFM were obtained from stock culture and placed in plastic jars with screen bottoms. The eggs were collected, sifted to remove parts of insects and frass and placed in Petri dishes.

\subsection{Trichogramma spp. Rearing Procedure}

Trichogramma spp. were permanently reared on MFM eggs in the laboratory in a room maintained at $24 \pm 1{ }^{\circ} \mathrm{C}, 70 \pm 5 \%$ r.h, and 14:10 (L:D). Trichogramma evanescens Westwood 1833, Trichogramma brassicae Bezdenko 1968, and Trichogramma pintoi Vogelé 1982 (Hymenoptera: Trichogrammatidae) used in the experiments were obtained from the Department of Plant Protection of the Faculty of Agriculture of Ankara University. Parasitoid cultures were started by using individual females on eggs of $E$. kuehniella and kept in glass vials $(8$ by $2 \mathrm{~cm})$ in the same room. The females tested were 2 to 3 hours old, fed with honey, mated and not contacted with the host eggs prior to testing. Fresh eggs (less than 24 hours old) of MFM were glued on pieces of white cardboard $(2$ by $5 \mathrm{~cm})$ and put into the vessels $(8 \mathrm{by} 2 \mathrm{~cm})$. These eggs were presented at the same time to a single female of the Trichogramma species for parasitization for 24 hours and placed in the environmental chamber and then were discarded.

\subsection{Feeding tests}

Experimental Design: Eight food options (A: No food, B: Flower, C: Pine, D: Citrus, E: Chestnut, F: Sunflower, G: Cotton and $\mathrm{H}$ : Sugar) were used for dietary treatments. The honey sources and sugar were regularly given to females wasps and unfed wasps were used as a control.

Each honey and the other treatments (no food and sugar) were compared as food for Trichogramma spp females. Flower, pine, citrus, chestnut, sunflower, and cotton honeys were obtained from the Faculty of Agriculture, Erciyes University. Each food was tested in three independent experiments in glass tubes $(8$ by $2 \mathrm{~cm})$, namely with diluted honey, with sugar, and with no food only. In tests with honey, a small piece of cotton moistened with the dilute honey was placed into each glass test tube. The food was renewed every second day.

To test the ability (parasitization, longevity) of individuals of each of the three Trichogramma species reared on different honeys, approximately 50 E. kuehniella fresh eggs glued on a cardboard was place in glass vials $(10 \mathrm{~cm} \times 3 \mathrm{~cm})$ and were separately offered to a single, newly emerged $(0-24 \mathrm{~h})$ and mated Trichogramma female of each species for one day. After plugged with a ventilated stopper, the vials were then placed in a randomized block trial design with 10-12 replicates. The females of each Trichogramma species were removed after this time of exposure and the number of parasitized eggs was counted. Longevity was determined by counting the number of adults each day until death. The food source was replaced daily unless otherwise indicated. Then each vial was examined carefully to determine the female longevity, parasitization, adult development, and sex ratio.

Data were analyzed using one-way variance analysis (ANOVA) with food sources being used as a factor and the number of parasitized eggs, number of total emerged adults and number of total females as dependent variables (PROC GLM) (SPSS 1999). The homogeneity of the variance was evaluated with the Levene's test. Before statistical analysis, all data were transformed into the square roots; Tukey-HSD was used as a means of separation when significant differences occurred (SPSS 1999). The life table statistics were calculated using data from adult survival studies. The mean survival rates were calculated using the KaplanMeier survival analysis (Kaplan \& Meier 1958). Differences in survival rates were compared with Breslow method (Generalized Wilcoxon) (Gehan 1965).

\section{Results and Discussion}

\subsection{Fecundity}

All of the honey had nutritional qualities and there is a potential to rear this insect on honey. Reproductive success in the Trichogramma species varied slightly when fed on different honey, but fecundity was not affected markedly (F, df, P>0.05). The effects of food on the parasitization of T. pintoi are shown in Figure 1. The mean fecundity (total offspring) or parasitism was between 29.0 and 36.7 per female; the highest values for honey F (Sunflower) were not significantly different from the other kinds of honey $(\mathrm{F}=1.162$, df $=7, \mathrm{P}>0.05)$. In $T$. evanescens, the mean fecundity was between 25.1 and 28.8 per female; the 
highest values for honey $\mathrm{C}$ (Pine) were not significantly different from the other kinds of honey $(\mathrm{F}=0.289, \mathrm{df}=7, \mathrm{P}>0.05)(\mathrm{Figure}$ 2). The number of parasitized hosts decreased to a comparatively constant level from honey $\mathrm{C}$ (Pine), to honey D (Citrus), and to honey B (Flowers).

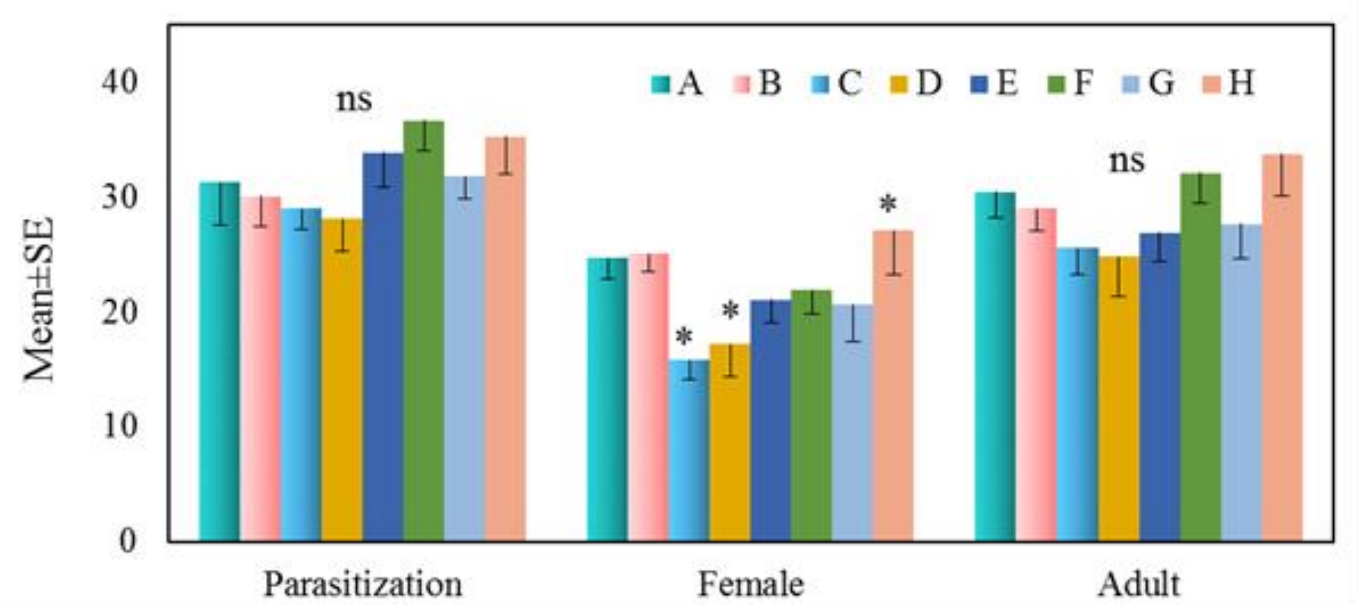

Figure 1- The mean number of parasitization of $T$. pintoi when reared on food sources. The asterisks in the columns indicate that there was significant difference at a $5 \%$ probability level by the Tukey test, ns: non-significant differences. (A: No food, B: Flowers, C: Pine, D: Citrus, E: Chestnut, F: Sunflower, G: Cotton, and H: Sugar)

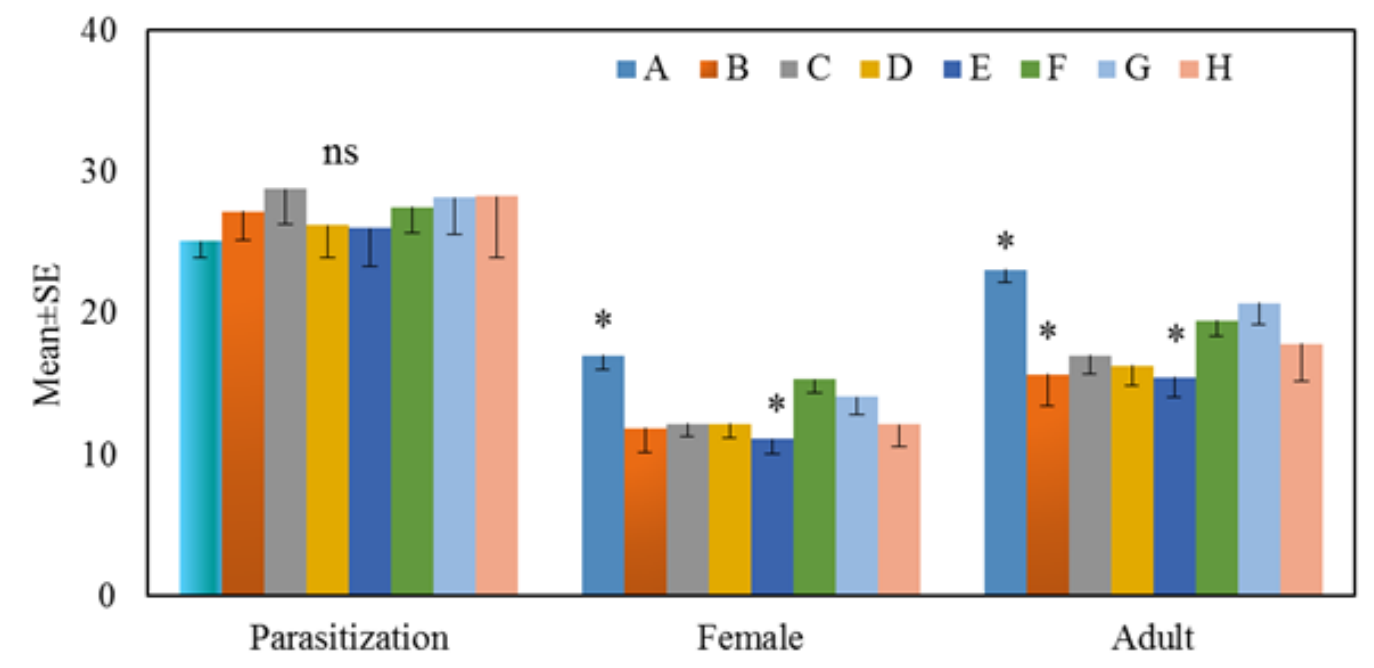

Figure 2- The mean number for parasitization of T. evanescens when reared on food sources. The asterisks in the columns indicate that there was significant difference at a $5 \%$ probability level by the Tukey test, ns: non-significant differences. (A: No food, B: Flowers, C: Pine, D: Citrus, E: Chestnut, F: Sunflower, G: Cotton and H: Sugar)

Regarding T. brassicae, the parasitization is shown in Figure 3. The number of offspring produced by T. brassicae females not differed significantly with the feeding treatment $(\mathrm{F}=1.903, \mathrm{df}=7, \mathrm{P}>0.05)$. There is no difference since $\mathrm{P}>0.05)$. The mean fecundity was between 29.5 and 39.4 per female for honey D (Citrus) and A (No food), respectively. A large difference was found in fecundity among females. Wasps had the highest parasitization when fed on D (Citrus) and A (No food) and the lowest in the other feeding treatments, particularly in G (Cotton) honey and in H (Sugar). The mean fecundity of the females, provided with honey for a day and then allowed to oviposit for one day, was similar to unfed females. The number of parasitized eggs (Figure 3) indicated that T. brassicae is more fecund than T. evanescens and T. pintoi.

Reproductive success in the Trichogramma species varied only slightly when fed on different kinds of honey, the mean fecundity or parasitism not being significantly different. It was found that when the T. euproctidis females were fed on artificial foods and flowers nectars, the females fed with sucrose, honey and dog-fennel had higher parasitization than other nutrients (Tuncbilek et al. 2012). These results are consistent with other studies that addressed the fecundity of Trichogramma where sugar was supplied and showed change or no increase in parasitism (Heimpel \& Jervis 2005; Wade et al. 2008).

Contrary to our findings, many researchers have indicated that an increase in fecundity can happen when parasitoid wasps fed with different foods (Ashley \& Gonzalez 1974; Leatemia et al. 1995; Shearer \& Atanassov 2004). These findings recommend 
that habitat management should provide a continuous supply of sugar or nectars to parasitoids. The significance of sugar feeding could clearly be greater in the field than expected from the laboratory, where parasitoids are not so active and are maintained under adequate conditions (Steppuhn \& Wackers 2004; Winkler et al. 2006). However, owing to the tendency of the Trichogramma spp to be pro-ovigenic the availability of food will likely not always increase fecundity. It is much more probable that adults will survive long enough to place appropriate hosts for their eggs (Harvey et al. 2012).

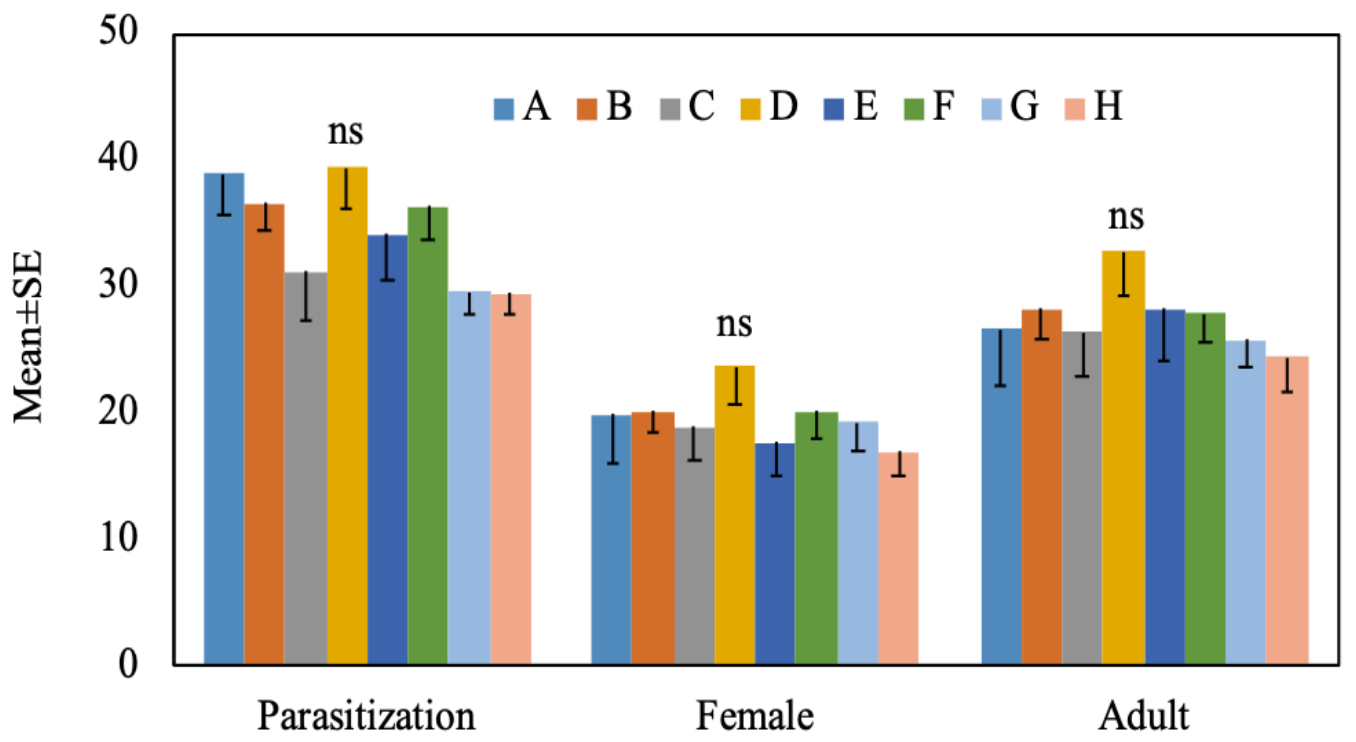

Figure 3- The mean number parasitization of $\boldsymbol{T}$. brassicae when reared on food sources. The asterisks in the columns indicate that there was significant difference at a $5 \%$ probability level by the Tukey test, ns: non-significant differences. (A: No food, B: Flower, C: Pine, D: Citrus, E: Chestnut, F: Sunflower, G: Cotton and H: Sugar)

\subsection{Female emergence}

The number of female emergence for Trichogramma pintoi was greater on the diet $\mathrm{H}$ (Sugar). It was significantly different from honey $\mathrm{C}$ (Pine) and $\mathrm{D}$ (Citrus) $(\mathrm{F}=2.463$, df $=7, \mathrm{P}<0.05)$ (Figure 1). There was a large variation in the results of the kinds of honey for female emergencies. Results were similar to the values observed for other honey and are not significantly different (P>0.05). In T. evanescens, the female emergence was greater on diet A (No food) (17.0). It was significantly different from the chestnut honey diet $(\mathrm{F}=2.965, \mathrm{df}=7, \mathrm{P}<0.05)$ (Figure 2). Regarding T. brassicae, the female emergence was greater on the diet $\mathrm{D}$ (Citrus) (23.7). It was not significantly different from the other honey (Citrus) $(\mathrm{F}=0.598$, df $=7$, P $>0.05)$ (Figure 3). Our findings support the study of Lundgren et al. (2002), who performed quality evaluation experiments for commercially reared Trichogramma spp, and found that the percentage emergence increased when Trichogramma adults received honey.

\subsection{Adult emergence}

Adult emergence of $T$. pintoi was greater with diet $\mathrm{H}$ (Sugar) (33.8), although it was not significantly different from honey $\mathrm{C}$ (Pine) or from D (Citrus) $(\mathrm{F}=1.285, \mathrm{df}=7, \mathrm{P}>0.05)$ (Figure 1). Results were similar to the values observed for other honeys and are not significantly different, though marginally more adults were produced for wasps fed on honey from flowers, sunflowers, and sugar ( $\mathrm{P}>0.05)$. In T. evanescens, the adult emergence was greater with diet A (No food) (23.1) It was significantly different from honey $\mathrm{B}$ (Flower) and $\mathrm{E}$ (Chestnut) $(\mathrm{F}=3.022$, df $=7, \mathrm{P}<0.05)$ (Figure 2). Results were similar to the values observed for other honey and are not significantly different, though slightly more adults were obtained for wasps fed on sunflower and, cotton honey and no food $(\mathrm{P}>0.05)$. The daily emergence trend was very comparable to the amount of daily parasitized eggs. These results accord with our previous study (Çınar et al. 2015).

Regarding T. brassicae, the adult emergence was a little bit greater with diet D (Citrus honey) (32.8). It was not significantly different from the other honey $(\mathrm{F}=0.593, \mathrm{df}=7, \mathrm{P}>0.05)$ (Figure 3$)$. Results were similar to the values observed for other honeys and are not significantly different, even though slightly more adults were produced for wasps that were fed with flower, chestnut, and sunflower $(\mathrm{P}>0.05)$. The number and sex ratio of progeny emerging from hosts parasitized by Trichogramma females fed on different kinds of honey did differ significantly. The sex ratio (female/male) of Trichogramma was affected by honey sources. The sex ratio varied from 1.86 to $3.76 ; 2.12$ to 3.42 and 1.67 to 2.97 for $T$. pintoi, $T$. evanescens, and T. brassicae, respectively. T. evanescens had a more significantly increased sex ratio than $T$. pintoi.

There has been extensive discussion of the use of additional food sources in agriculture to enhance biological control facilities for parasitoids and predators (Heimpel \& Jervis 2005). The provision of food in the field was reported to help parasitoids maintain their sugar resources and raise fecundity and parasitism (Tena et al. 2015). 


\subsection{Longevity}

Longevity in Trichogramma varied significantly when fed on different kinds of honey. Honey types provided to T. pintoi females significantly affected longevity. The highest longevity was recorded (6.91 \pm 0.8 days) on sugar. The shortest longevity was recorded on no food ( $2,00 \pm 0.0$ days) (Figure 4$)$. The longevity of parasitoids that were maintained with sugar was marginally higher than those kept on chestnut honey and no food.

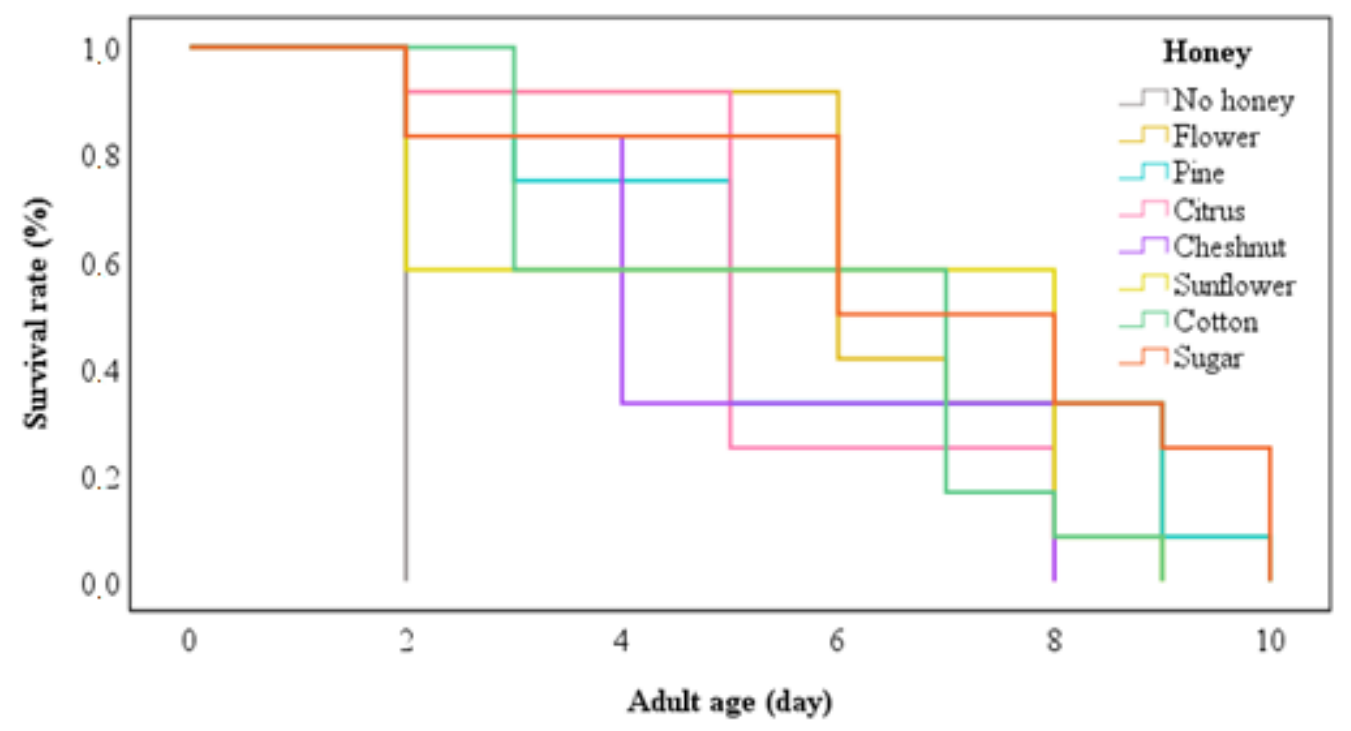

Figure 4- The survival rate of $T$. pintoi fed on different kinds of food sources $(n=12)$, Kaplan-Meier curves of survivorship in days for $T$. pintoi females fed on different kinds of honey

The longevity of $T$. evanescens provided with sunflower, flower, and cotton honey was significantly different than those given no honey $\left(\chi^{2}=41.06, \mathrm{df}=6, \mathrm{P}<0.001\right)$. Parasitoids lived a longer period of time when they were fed on sunflower honey

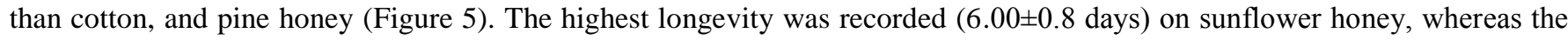
shortest longevity was recorded on no food ( $3.25 \pm 0.1$ days) when they had no access to honey. The shortest longevity was recorded on no food ( $3.25 \pm 0.1$ days). The longevity of parasitoids that were maintained with sugar was marginally higher than those kept on chestnut honey and no food.

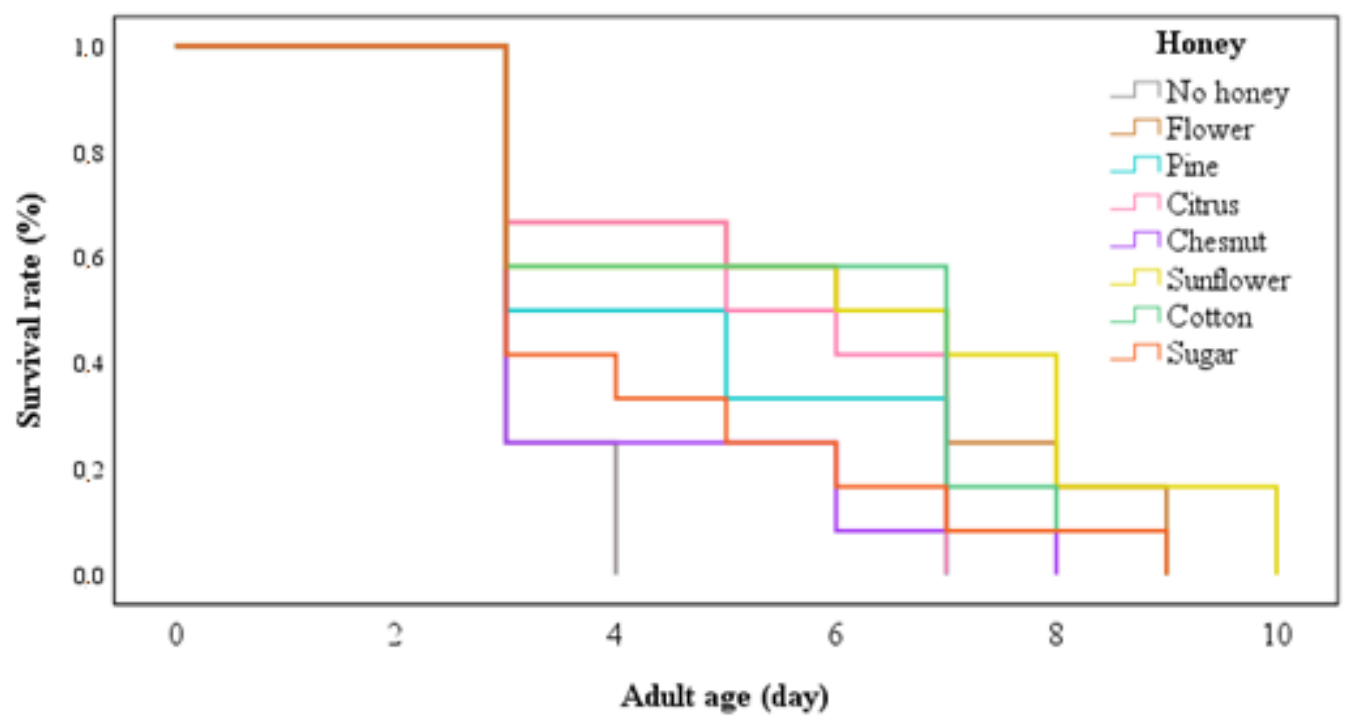

Figure 5- The survival rate of T. evanescens fed on different kinds of food sources $(n=12)$

Honey types provided to $T$. brassiace females significantly affected longevity. The highest longevity was recorded ( $8.71 \pm 1.2$ days) on sugar. The shortest longevity was recorded on no food ( $1.83 \pm 0.3$ days) (Figure 6$)$. The longevity of parasitoids that were maintained with sugar was marginally higher than those kept on sunflower, pine honey, and no food. The longevity of $T$. brassiace provided with pine honey and no food was significantly different than those given other honey $\left(\chi^{2}=52.45, \mathrm{df}=6, \mathrm{P}<\right.$ 0.001) (Figure 6). The Trichogramma male was not observed. 
The survival curves of adult females of $T$. pintoi and T. evanescens (Figures 4 and 5) showed similar time patterns. The maximum female life expectancy was 10 days for $T$. pintoi and T. evanescens, and 15 days for T. brassiace. In spite of the similarity of the survival curves (T. brassicae), some minor differences could be observed (Figure 6). Although the availability of honey has clearly affected the life span of all three of the Trichogramma species, it did not markedly increase fecundity.

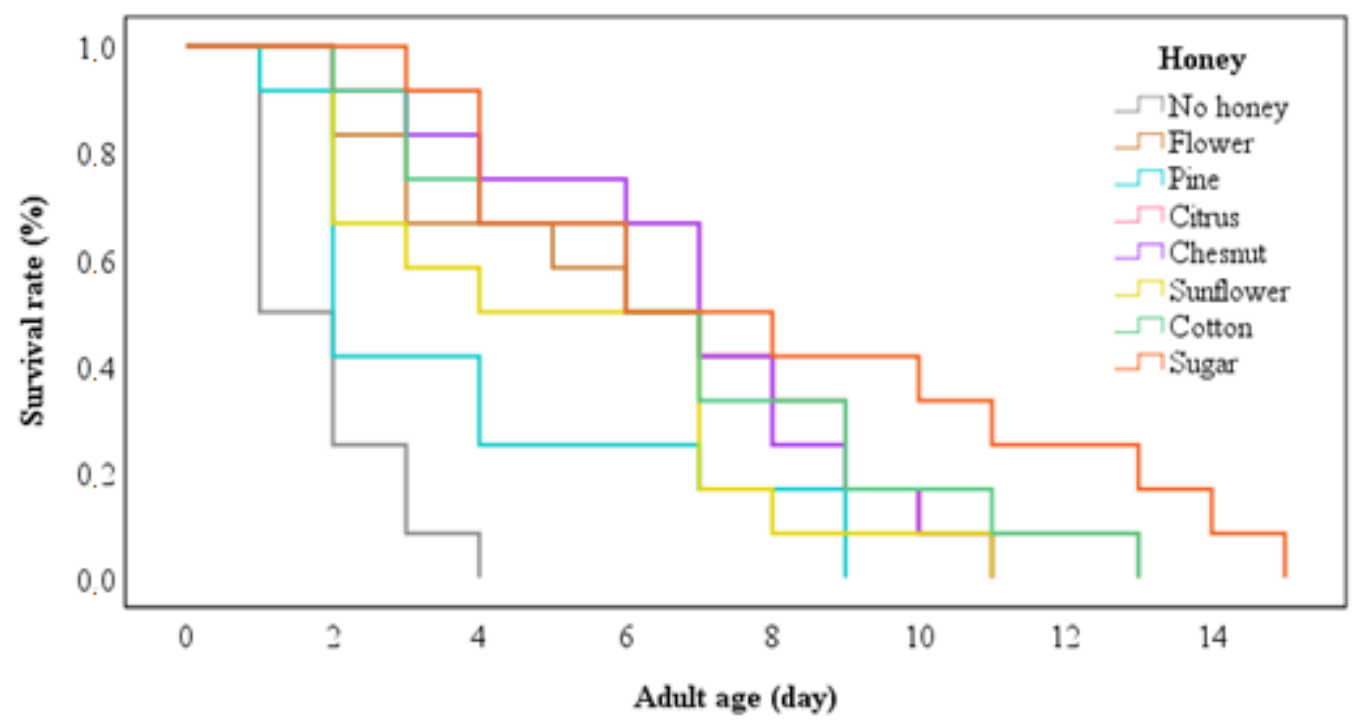

Figure 6- The survival rate of $T$. brassiace fed on different kinds of food sources $(n=12)$

The findings of the study indicated that the various kinds of honey had impressive effects on longevity in the Trichogramma species. There was a dramatic decrease in longevity when wasps were reared on chestnut honey. A similar amount of offspring was yielded within each species, however, the wasps had different longevity on the eight kinds of food examined. An earlier study (Wäckers 2001) observed a major shift in sugar quality in parasitoid C. glomerata longevity. There were important interspecific differences in earlier experiments when wasps were fed honey (Harvey 2008). In a previous study it was found that a major shift in sugar quality had a major impact on the longevity of the parasitoid C. glomerate (Wäckers 2001).

Our study provides new insight into the biology of Trichogramma spp which can be useful concerning the ability to use $T$. pintoi, T. evanescens and T. brassicae species in biological control. However, further testing should be done before a decision is made on which species is the appropriate agent for control of pests. Therefore, we conclude that almost all honey is adequate for rearing Trichogramma, except for chestnut, based on the biological parameters of parasitization, adult emergence, and female longevity. Overall, feeding Trichogramma on various honey had a slight effect on parasitization, but greater effect on longevity. Of the species of Trichogramma assessed, T. brassicae appears to be the most appropriate parasitoids for high parasitization and longer life. Further studies should target the efficiency of resource use in adult parasitoids derived from different diets in order to establish possible relations to certain life histories and reproductive strategies for these insects. In the same way, the approaches to mass rearing of these wasps for biological control and the unraveling of trait-mediated evolutionary constraints could be strengthened. It was concluded that different honey sources are effective on female longevity in the rearing of the Trichogramma species. In the current study, some honeys have been shown to be a more adequate food to maintain the development and reproduction of Trichogramma species.

\section{Acknowledgements}

This work has been supported by Erciyes University Scientific Research Projects Coordination Unit under grant number FYL2017-7304.

\section{References}

Alavarez-Suarez J M, Tulipani S, Romandini S, Bertoli E \& Battino M (2009). Contribution of honey in nutrition and human health: a review. Mediterranean Journal of Nutrition and Metabolism 3: 15-23 doi.org/10.3233/s12349-009-0051-6

Ashley T R \& Gonzales D (1974). Effect of various food substances on longevity and fecundity of Trichogramma. Environmental Entomology 3: 169-171 doi.org/10.1093/ee/3.1.169

Bourarach K \& Hawlitzky N (1989). Comparative study of the biological potential of Trichogramma evanescens Westwood and Trichogrammatoidea lutea Girault (Hymenoptera: Trichogrammatidae). Entomophaga 34: 95-104

Çınar N, Tuncbilek A S \& Bakır S (2015). Comparative effects of flower nectar and artificial diets on some biological aspects of the parasitoid species Bracon hebetor (Say.) (Hymenoptera: Braconidae). Egyptian Journal of Biological Pest Control 25(1): 233-236 
Echingo T \& Takenaka T (1974). Production of organic acids in honey by honey bees. Journal of Agriculture Chemical Society Japan 48: 225230

Gehan E (1965). A generalized Wilcoxon test for comparing arbitrarily singly-censored Samples. Biometrika 52: 203-223

Gheldof N, Wang X H \& Engeseth N J (2002). Identification and quantification of antioxidant components of honey from various floral sources. Journal of Agricultural and Food Chemistry 50: 5870-5877

Harvey J A (2008). Comparing and contrasting development and reproductive strategies in the pupal hyperparasitoids Lysibia nana and Gelis agilis (Hymenoptera: Ichneumonidae). Evolutionary Ecology 22: 153-166 doi.org/10.1007/s10682-007-9164-x

Harvey J A, Cloutier J, Visser B, Ellers J, Wäckers F L \& Gols R (2012). The effect of different dietary sugars and honey on longevity and fecundity in two hyperparasitoid wasps. Journal of Insect Physiology 58: 816-823 doi.org/10.1016/j.jinsphys.2012.03.002

Hassan S A (1993). The mass rearing and utilization of Trichogramma to control Lepidopterous pests. Achievements and outluk Pesticides Sciences 37: 287-391 doi.org/10.1002/ps.2780370412

Heimpel G E \& Jervis M A (2005). Does floral nectar improve biological control by Parasitoids? 267-304. In: E L Wacker, P C van Rijn \& J. Bruin (Eds.). Plant-Provided Food for Carnivorous Insects: A Protective Mutualism and Its Applications, Cambridge University Press, Cambridge doi.org/10.1017/cbo9780511542220.010

Hohmann C L R, Luck F, Oatman E R \& Platner G R (1989). Effects of different biological factors on longevity and fecundity of Trichogramma platneri Nagarkatti (Hymenoptera: Trichogrammatidae). Anais da Sociedade Entomologica do Brasil 18: (supplement) 61-70 doi.org/10.37486/0301-8059.v18isupl..612

Jervis M A \& Kidd N A C (1992). The dynamic significance of host-feeding by parasitoids - what modellers ought to consider. Oikos 62: $97-$ 99 doi.org/10.2307/3545454

Kaplan E L \& Meier P (1958). Nonparametric estimation from incomplete observations. Journal of the American Statistical Association 53: 457-481 doi.org/10.1007/springerreference_205495

Leatemia J A, Laing J E \& Corrigan J E (1995). Effects of adult nutrition on longevity, fecundity, and offspring sex ratio of Trichogramma minutum Riley (Hymenoptera: Trichogrammatidae). The Canadian Entomologist 127: 245-254 doi.org/10.4039/ent127245-2

Lundgren J G, Heimpel G E \& Bomgren S A (2002). Comparison of Trichogramma brassicae (Hymenoptera: Trichogrammatidae) augmentation with organic and synthetic pesticides for control of cruciferous Lepidoptera. Environmental Entomology 31: 1231-1239 doi.org/10.1603/0046-225x-31.6.1231

Marec F, Kollarova I \& Pavelka J (1999). Radiation-induced inherited sterility combined with a genetic sexing system in Ephestia kuehniella (Lepidoptera: Pyralidae). Annual Entomology Society of America 92: 250-259 doi.org/10.1093/aesa/92.2.250

Martos I, Ferreres F \& Tomás-Barberán F A (2000). Identification of flavonoid markers for the botanical origin of eucalyptus honey. Journal of Agricultural and Food Chemistry 48: 1498-1502 doi.org/10.1021/jf991166q

Shearer P W \& Atanassov A (2004). Impact of peach extrafloral nectar on key biological characteristics of Trichogramma minutum (Hymenoptera: Trichogrammatidae). Journal of Economic Entomology 97: 789-792 doi.org/10.1093/jee/97.3.789

Smith S M (1996). Biological control with Trichogramma: advances, successes, and potential of their use. Annual Review of Entomology 41: 375-406 doi.org/10.1146/annurev.en.41.010196.002111

Somchoudhury A K \& Dutt N (1988). Evaluation of some flowers as a nutritional source of Trichogramma spp. Indian Journal of Entomology 50: 371-373

SPSS (1999). SPSS Version 10.0. SPSS Inc, 233 S. Wacker Drive, Chicago, Illinois

Steppuhn A \& Wackers F L (2004). HPLC sugar analysis reveals the nutritional state and the feeding history of parasitoids. Functional Ecology 18: 812-819 doi.org/10.1111/j.0269-8463.2004.00920.x

Tena A, Pekas A, Cano D, Wäckers F L \& Urbaneja A (2015). Sugar provisioning maximizes the biocontrol service of parasitoids. Journal of Applied Ecology 52: 795-804 doi.org/10.1111/1365-2664.12426

Tuncbilek A S, Çınar N \& Canpolat U (2012). Effects of artificial diets and floral nectar on longevity and progeny production of Trichogramma euproctidis Girault (Hymenoptera: Trichogrammatidae). Turkish Journal of Entomology, 36(2): 183-191

Van Lenteren J C (2012). The state of commercial augmentative biological control: plenty of natural enemies, but a frustrating lack of uptake. BioControl 57: 1-20

Waage J K (1990). Ecological theory and the selection of biological control Agents, 135-157. In: M Mackauer, L E Ehler \& J Roland (Eds.). Critical Issues Biological Control. Intercept, Andover

Wäckers F L (2001). A comparison of nectar- and honeydew sugars with respect to their utilization by the hymenopteran parasitoid Cotesia glomerata. Journal of Insect Physiology 47: 1077-1084

Wade M R, Zalucki M P, Wratten S D \& Robinson K A (2008). Conservation biological control of arthropods using artificial food sprays: current status and future challenges. Biological Control 45: 185-199

Wellinga S \& Wysoki M (1989). Preliminary investigation of food source preferences of the parasitoid Trichogramma platneri Nagarkatti (Hymenoptera, Trichogrammatidae). Anzeiger für Schadlingskunde Pflanzenschutz Umweltschutz, 62: 133-135

Winkler K, Wackers F L, Bukovinszkine-Kiss G \& Van Lenteren J C (2006). Sugar resources are vital for Diadegma semiclausum fecundity under field conditions. Basic and Applied Ecology 7: 133-140

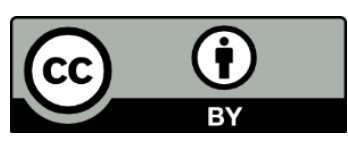

(C) 2021 by the authors. Licensee Ankara University, Faculty of Agriculture, Ankara, Turkey. This article is an open access article distributed under the terms and conditions of the Creative Commons Attribution (CC BY) license (http://creativecommons.org/licenses/by/4.0/). 